IZA DP No. 5508

Asymmetric Information in the Labor Market, Immigrants and Contract Menu

Saibal Kar

Bibhas Saha

February 2011 


\title{
Asymmetric Information in the Labor Market, Immigrants and Contract Menu
}

\author{
Saibal Kar \\ Centre for Studies in Social Sciences, Calcutta \\ and IZA
}

Bibhas Saha

University of East Anglia

\section{Discussion Paper No. 5508 \\ February 2011}

\author{
IZA \\ P.O. Box 7240 \\ 53072 Bonn \\ Germany \\ Phone: +49-228-3894-0 \\ Fax: +49-228-3894-180 \\ E-mail: iza@iza.org
}

\begin{abstract}
Any opinions expressed here are those of the author(s) and not those of IZA. Research published in this series may include views on policy, but the institute itself takes no institutional policy positions.

The Institute for the Study of Labor (IZA) in Bonn is a local and virtual international research center and a place of communication between science, politics and business. IZA is an independent nonprofit organization supported by Deutsche Post Foundation. The center is associated with the University of Bonn and offers a stimulating research environment through its international network, workshops and conferences, data service, project support, research visits and doctoral program. IZA engages in (i) original and internationally competitive research in all fields of labor economics, (ii) development of policy concepts, and (iii) dissemination of research results and concepts to the interested public.
\end{abstract}

IZA Discussion Papers often represent preliminary work and are circulated to encourage discussion. Citation of such a paper should account for its provisional character. A revised version may be available directly from the author. 
IZA Discussion Paper No. 5508

February 2011

\section{ABSTRACT \\ Asymmetric Information in the Labor Market, Immigrants and Contract Menu*}

Immigrant workers and their labor force participation in host countries have received critical attention in all concerned disciplines, principally owing to its strong implications for well-being of natives. The ageing population in many rich countries and several related and unrelated issues including global integration, pension provisions or security threats keeps immigration under continuous impact evaluation. However, of the several studies that dealt with patterns and consequences aspects of labor migration, only a handful discusses asymmetric information across transnational labor markets despite agreement that a standardized screening mechanism is unavailable. At the same time, several empirical studies show that immigrants are proportionally overrepresented in self-employment, vis-à-vis natives of equivalent skill levels. We try to explain this phenomenon based on asymmetric information in the host country labor market. We focus on the design of a contract menu by the employers, which when offered to a mixed cohort of immigrants facilitates self-selection in favor of paid employment or the outside option of self-employment/entrepreneurship. We also discuss countervailing incentives among the mixed cohort.

JEL Classification: $\quad$ D82, J23, J24, J41, J61

Keywords: immigrants, asymmetric information, labor contracts, self-employment, incentive compatibility

Corresponding author:

Saibal Kar

Centre for Studies in Social Sciences, Calcutta

R-1, B.P. Township

Kolkata 700094

India

E-mail: saibal@cssscal.org

\footnotetext{
* Saibal Kar is grateful to the Poverty and Economic Policy Network, Canada for a visiting grant to the University of East Anglia, UK.
} 


\section{Introduction}

Existence of asymmetric information in the labor market generates a wide variety of implications for both firms and workers. In particular, for those who are fresh in the labor market, information asymmetry in the labor market is intrinsic to a situation where (at least initially) employers do not know the productivity levels of potential employees. It can arise if the markets are isolated such that "information does not ordinarily flow across them (or does not flow costlessly and freely)” (Katz and Stark, 1987, p. 718). Clearly, the problem of asymmetric information may turn out to be of monumental significance when it comes to employing migrant labor - the ones which originate in spatially separated, culturally and information-wise distant countries. ${ }^{1}$ The intensified mobility of labor in search of jobs across national borders is an important constituent of the process of global integration and this has significantly affected the labor market operations at both ends. This paper focuses on the impact on recipient countries only, with lack of readily verifiable information instrumental in shaping employee and employer behavior. In the presence of asymmetric information, signaling by workers and screening by employers are the only two devices that reinstate symmetry. In fact, it is well known due to Spence $(1973,1974)$ that better quality workers can signal at a lower marginal cost of signaling activity. Later, Stiglitz (1975) offered a screening device by virtue of which more able workers can take an accurate test at a fixed cost. ${ }^{2}$ We discuss an alternative - the offer of a contract menu by the employers which can overcome

\footnotetext{
${ }^{1}$ In this context, Chau and Stark (1999, p. 455) note, "whatever workers may take with them when they migrate, they cannot possibly transfer their home countries' information structure”. Also see Friedberg (2000) with respect to migrants to Israel.

${ }^{2}$ In Stiglitz's model the firms are less responsive to profit possibilities - a condition that is relaxed in Yabushita (1983), who show among other things that striking similarities exist between Stiglitz and Spence models.
} 
informational asymmetry with particular reference to immigrants.

It should be noted that while screening devices may be tenable for labor originating within the boundaries of one country or countries with erstwhile colonial connections, a sweeping applicability of such devices remain inconceivable even in this high age of standardization and information flow. Thus, if more generally, the problem is cast as one with lack of interpretable and verifiable information then large migrantreceiving countries such as USA, Canada, Germany, France or Australia are expected to suffer initially from high degrees of uncertainty regarding the true skill level of many immigrant workers. It is best borne out in several studies by Dustmann and others (2005a, 2005b, 2003) that language proficiencies and cultural distances shape labor market behavior of immigrants to a large extent. In a sense, absence of readily interpretable attributes lead to similar information blackouts as one observes in the context of rural-urban migration, which makes asymmetric information generic to all forms of spatial migration of labor. Therefore, if asymmetric information is substantial and pre-employment signaling and screening are costly and/or inefficient, employers tend to offer pooled wage across mixed immigrant cohorts until the true skill levels are discovered (Katz and Stark, 1987; Chau and Stark, 1999; etc). This is an exposition of the nature of wage contracts employers prefer to enter into in the presence of asymmetric information and leaves the better types adversely affected.

But, there can be more sophisticated contracts. In this thought experiment, we use a mixed cohort of immigrants to many OECD countries as the target group on which a better designed contract is implemented. However, the results should be meaningful for domestic labor markets as well where ready interpretability of skills is difficult. 
Similarly, we assumed an outside option of self-employment for the immigrants, which serves as an example amidst several other possibilities. ${ }^{3}$ We stick to self-employment as a broad category primarily because there exists substantial evidence in favor of successful, multigenerational self-employment practices among immigrants, which we discuss shortly. The exercise is based on the assumption that native employers do not (or, minimally) encounter similar problems with native job applicants, as credentials of locals are readily interpretable and verifiable. On the same note, the study would concentrate only on those who migrate for jobs and do not engage in education/training in the host country. ${ }^{4}$

We formulate that there is a pool of immigrant workers whose productivity is unknown to the native firms. But this pool consists of two types of workers, high productivity and low productivity. The high productivity workers also have an outside option in the form of self-employment, while the low productivity workers entirely depend on the spot labor market offering a fixed pooled wage. The firm hires either from the spot market, or by offering individualized contracts. The first option yields a fixed profit regardless of the worker's productivity. The second option can potentially yield higher profit if the worker is turned out to be high productivity type; but then information rent has to be conceded to screen the workers via incentive compatible contracts. ${ }^{5}$ We wish to study when the firm will opt for the contract route and when for the spot market route. When the spot market is preferred, the high productivity immigrants will opt for

\footnotetext{
${ }^{3}$ Individuals are "self-employed if they earn no wages or salary, but derive their incomes by exercising their profession or business on their own account and/or for their own risk" (De Wit, 1993, p. 2).

${ }^{4}$ See Kar (2009) for a characterization of occupational patterns among immigrants in the presence of asymmetric information in the labor market. High self-employment participation among immigrants turns out to be a result of statistical discrimination by the employers.

${ }^{5}$ In a related context Bester (1989) shows that long-term incentive compatible wage contracts offer higher utility compared to spot-market wages, and in effect the long-term wage contracts are rationed.
} 
self-employment. Potentially, this generates an occupational distribution in the economy, and we can identify the underlying parameters of this distribution.

One may expect on the basis of the standard results of the agency theory that the high productivity type will be employed at the first best level, and he will also be paid a slightly higher wage above his self-employment income, while the low productivity type will be under-employed and paid only his reservation utility. If this intuition were correct the high productivity type would be hired slightly less often than under full information. But that is not the case. The combination of asymmetric information and selfemployment opportunity may change this commonly accepted intuition. While information rent or incentive cost inevitably arises due to asymmetric information, the self-employment option introduces certain countervailing incentives. As a result, information rent can sometimes disappear, and even be reversed from the high productivity type to the low productivity type (see Lewis and Sappington, 1989; Maggi and Rodriguez-Clare, 1995 for more on countervailing incentives). When the information rent disappears, the firm's profit rises; in this sense countervailing incentives are beneficial for the firm. But on the other hand, when the high productivity type is under-employed and the low-productivity worker is given information rent, firm's profit significantly falls. Tension between these two forces makes the firm opt for spot market more often that it would if the immigrant workers did not have the self-employment option. Since the spot market is relied upon more often, in equilibrium high productivity immigrant workers will also be self-employed more often.

Most other work in this area, however, deals with characterization of job contracts when asymmetric information prevails on the 'state of nature' facing the firm 
(for example, Azariadis, 1983; Ferguson and Jhang, 1994; etc. discuss employment contracts when firms have better knowledge of their market conditions than workers do). Apart from that, some consider cases where firms compete with each other to attract selfproclaimed high-ability workers whose true productivity is unknown and conclude that such workers will signal if the wage offers are substantially high in the presence of competition (see Janssen, 2002).

Our approach differs considerably from these types of studies in the sense that the contract menu we device induces the workers to reveal their true types, and hence influences self-selection in the labor market. This should, on the one hand, lower employers' dependence on other screening devices, and on the other reduce direct costs borne by both employers and employees owing to asymmetric information. Moreover we identify the presence of countervailing incentives and incentive reversals depending upon the range within which labor productivity at the firm level varies and some of these results are rather dramatic. As already mentioned, this may also provide a strong explanation as to why for north America, western Europe and other developed countries empirical estimates show higher self-employment rate among immigrants vis-à-vis the native born (Bates, 1997; Clark and Drinkwater, 2000; Li, 1997; Yuengert, 1995; Fairlie and Meyer, 1996, 2003; etc., for USA and UK; Razin, 1992, a case study for Israel with respect to Asian, African, East European and N. American immigrants; Kidd, 1993 for Australia etc). ${ }^{6}$ All of these studies emphasize that in many rich countries, immigrants as well as ethnic minorities are proportionately over-represented in self-employment; i.e. the immigrant self-employment rate exceeds that of the native population. Of course, there

\footnotetext{
${ }^{6}$ Fairlie (1996), for example, shows that the Korean American men and women have self-employment rates of 27.9 and $18.9 \%$, respectively, and followed by Lebanese immigrants and so on. Kidd (1993) shows that among skilled Australian immigrants (collegiate), self-employment rate exceeds that of natives.
} 
are a number of other explanations for high rate of minority and immigrant selfemployment in these countries. They include, labor market discrimination (Borjas and Bronars, 1989; Fairlie 1996, etc.), enclave effects and language proficiency (Borjas, 1986, although lacks support from later studies viz. Clark and Drinkwater, 2000; Yeungert, 1995, etc), and source country cultural traits (Bonacich and Modell, 1981; Bates, 1997; Borjas, 1987; Constant and Zimmerman, 2006; Duleep and Regets, 1997; Dustmann et al, 2005a, 2005b, 2003; Fairlie, 2005; Funkhouser and Trejo, 1995; LaLonde and Topel, 1992; Light, 1984).

The remaining part of the paper is designed as follows. Section 1 offers the general formulation of the problem, section 2 introduces asymmetric information and the following subsections fully characterize the nature and efficiency of labor market contracts. Section 3 discusses possibilities of countervailing incentives and section 4 concludes.

\section{The Model}

Consider a firm and a continuum of workers with a mass of 1 . The firm is assumed to be price taker in the product market, but has market power in the labor market. Its market power is reflected in the fact that it can offer individualized contracts to workers depending on their characteristics and such contracts are take-it-or-leave-it offers. For simplicity, labor is the main input for production and the production function is linear. The profit function facing the firm is:

$$
\pi=a l-w .
$$

Here $\pi$ denotes profit, $l$ is the amount of labor employed, $a$ is the labor productivity in the firm and $w$ is the wage. The firm has two options: hire from the spot market or hire 
through contracts. The spot market hiring yields a profit of $\pi_{0}$. Since this is the least the firm can make, it becomes its reservation profit.

In the contract market, the firm has the opportunity to tailor its offer in terms of the productivity of the worker and thus can earn greater profit; but it does not have complete information about the workers. In particular, it cannot discern the true type of the workers who vary in terms of their disutility from work. ${ }^{7}$ We assume that Mother Nature randomly draws a disutility parameter $(\mu)$ affecting the worker’s preference. However, after this draw only the workers themselves know about their disutility. There are only two types of workers - one with greater disutility and the other with smaller disutility. The greater disutility worker becomes a 'low productivity worker' and therefore he is called the 'low' type. Conversely, the smaller disutility worker is called the 'high' type for his ability to contribute more to the firm's output. They have the following utility functions:

Utility function of the high type: $\quad u_{H}=w-\mu_{H} \frac{l_{H}^{2}}{2}$

Utility function of the low type: $\quad u_{L}=w-\mu_{L} \frac{l_{L}^{2}}{2}$

As stated, we assume $\mu_{L}>\mu_{H}$. Without loss of generality set $\mu_{H}=1$. The probability of being high or low type is $p_{1}$ and $p_{2}$ respectively; $p_{1}+p_{2}=1$. These probabilities are common knowledge.

We also assume that these two types also vary with respect to their outside options. The low type can work in an outside sector and earn zero reservation utility. But

\footnotetext{
${ }^{7}$ As we have discussed earlier, it may be because the workers are young and that the employer does not have requisite information regarding their skill types, and/or the $a$ priori screening system is not efficient to allow immediate identification of the true skill types of those who apply for the jobs.
} 
the high type can work as self-employed and thus his reservation utility will depend on his self-employment production function. We assume that under self-employment production function is given as $Q=b l^{8}{ }^{8}$ Further, $b<a$. That is, technologically a firm is superior to self-production. The self-employment option gives him a reservation utility of $\bar{u}_{H}=\operatorname{Max}_{l_{H}}\left[b l_{H}-\mu_{H} \frac{l_{H}^{2}}{2}\right]=\frac{b^{2}}{2 \mu_{H}}$.

If the firm wishes to offer an employment contract to the worker, especially the high type, it has to make him at least as well off as he would be under self-employment. With this setup, we wish to derive the firm's optimal wage-employment contract, and also determine when the firm will go for the contract route of hiring instead of the spot market. Needless to say, under asymmetric information the optimal contract will be in general (but not necessarily) second-best, and to what extent this contract deviates from the first best is of some interest.

The first best contract corresponds to the situation where the firm along with the workers learns the realization of $\mu$. Given the reservation payoff structure of our model, the profit maximizing first-best contract $\left(l_{i}{ }^{*}, w_{i}{ }^{*}\right)$ for type $i,(i=H, L)$ is: $l_{H}^{*}=\frac{a}{\mu_{H}}$, $w_{H}^{*}=\frac{a^{2}+b^{2}}{2 \mu_{H}}$ and $l_{L}^{*}=\frac{a}{\mu_{L}}$, with $w_{L}^{*}=\frac{a^{2}}{2 \mu_{L}}$. Note that $l_{L}^{*}<l_{H}^{*}$. This property of the first best contract will be carried onto the second best contract as well. ${ }^{9}$

\footnotetext{
${ }^{8}$ We can rationalize the difference in the outside options of the two types in two ways. Both can at worst rely on a competitive market or some sort of public transfer and ensure themselves zero utility; but the high type has the additional option of self-employment and the low type does not. This can be for their differential access to technology, or credit. In that case access is clearly correlated with their distutility from work. Alternatively, we can assume that both types have the option of working as self-employed; but the low type's disutility parameter is so high (relative to $b$ and $F$ ) that self-employment is never profitable for them.

${ }^{9}$ This point can be formally proved. But since the proof is standard in information economics, we omit this.
} 
The firm's first best profit is $\pi^{*}{ }_{H}=\frac{a^{2}-b^{2}}{2 \mu_{H}}$ and $\pi^{*}{ }_{\mathrm{L}}=\frac{\mathrm{a}^{2}}{2 \mu_{\mathrm{L}}}$. By comparing $\pi_{H}{ }^{*}$

and $\pi_{0}$ we conclude that there exists a value of $b$, say $\bar{b}$, where $\bar{b}=\sqrt{a^{2}+2 \mu_{H} \pi^{0}}<a$,

such that $\pi_{\mathrm{H}}{ }^{*}<\pi_{0}$ at $\mathrm{b}>\overline{\mathrm{b}}$. At other values of $b$, hiring a high productivity worker (via contract) is preferable to hiring from the spot market. As for low productivity worker, the contract route is preferable only if $\pi_{L}{ }^{*} \geq \pi^{0}$.

\section{Asymmetric Information}

Under asymmetric information, the firm offers a menu of contracts $\left\{\left(l_{H}, w_{H}\right)\right.$, $\left.\left(l_{L}, w_{L}\right)\right\}$. This has the advantage of ensuring the acceptance of offers as the contract will induce self-selection. The firm's optimal menu contract can be derived by solving the following problem:

Firm's Problem: $\quad$ Max $E \pi=p_{1}\left\{a l_{H}-w_{H}\right\}+p_{2}\left\{a l_{L}-w_{L}\right\}$

subject to, $\quad I C_{H}: \quad w_{H}-\mu_{H} \frac{l_{H}^{2}}{2} \geq w_{L}-\mu_{H} \frac{l_{L}^{2}}{2}$

$$
\begin{aligned}
& I C_{L}: \quad w_{L}-\mu_{L} \frac{l_{L}^{2}}{2} \geq w_{H}-\mu_{L} \frac{l_{H}^{2}}{2} \\
& I R_{H}: \quad w_{H}-\mu_{H} \frac{l_{H}^{2}}{2} \geq \frac{b^{2}}{2 \mu_{H}} \\
& I R_{L}: \quad w_{L}-\frac{\mu_{L} l_{L}^{2}}{2} \geq 0
\end{aligned}
$$

The constraints (4.1)-(4.2) are incentive compatibility (IC) constraints that ensure self-selection by each type from the menu of contracts. Constraints (5.1) and (5.2) describe the individual rationality constraints (IR) for both types. Of this, the constraint 
(5.1) holds special interest for us. For standard asymmetric information problems, the reservation utility of the high and low types is generally same. Therefore, any contract that is acceptable to the low type is also acceptable to the high type. This implies that the high type is to be conceded information rent and the low type is given only his reservation utility. Invariably, the low type’s employment will be distorted. In our context, the reservation utility of the high type is different, and moreover, it varies depending on his self-employment productivity $b$. This gives rise to the possibility that the high type may not always have informational advantage. This will depend on the size of $b$ relative to $a$.

\subsection{Optimality of the first best contract}

First we note that there exists a range of $b$ in which the first best contract remains optimal even under asymmetric information. Define $(\tilde{l}, \tilde{w})$ as the common value of $l$ and $w$ that simultaneously bind $I R_{H}$ and $I R_{L}$. By setting $\mu_{H} \frac{\tilde{l}^{2}}{2}+\frac{b^{2}}{2 \mu_{H}}=\mu_{L} \frac{\tilde{l}^{2}}{2}$, we solve for

$$
\tilde{l}=\frac{b}{\sqrt{\mu_{H}}}, \quad \widetilde{w}=\frac{b^{2} \mu_{L}}{2 \mu_{H}}
$$

We show that if the first best employment levels are such that $l_{L}^{*} \leq \tilde{l} \leq l_{H}^{*}$, the first best contract will remain optimal. The low type (which suffers high disutility from work) will find the high type's employment too high to match the associated high wage, and the high type will find the low type's offer too poor to yield his higher reservation utility. Thus, the first best offers will be both incentive compatible and individually rational. 
Proposition 1: $\quad$ (a) If $b \in\left[\frac{a \sqrt{\mu_{H}}}{\mu_{L}}, \frac{a}{\sqrt{\mu_{H}}}\right]$ the optimal menu will consist of the first best contracts.

(b) But if $b<\frac{a \sqrt{\mu_{H}}}{\mu_{L}}$ the menu of the first best contracts is not incentive compatible for type $H$. Similarly, if $b>\frac{a}{\sqrt{\mu_{H}}}$, the first best menu is not incentive compatible for type $L$.

Proof: See Appendix 1.

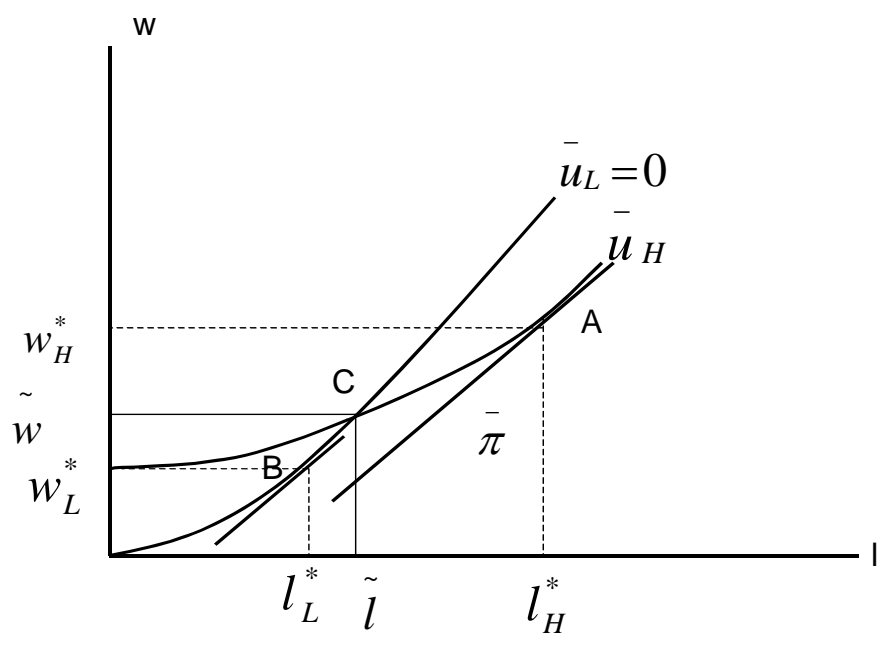

Figure 1: Optimality of the first best contracts 
In Figure 1 we depict the situation where the first best contracts form the optimal menu. Two indifference curves are so drawn that they correspond to the reservation utility levels, 0 for type $L$ and $\bar{u}_{H}$ for type $H$. Of these two, the indifference curve of type $H$ shifts up as the value of $b$ increases and thus causes $(\tilde{l}, \tilde{w})$ also to increase, which is given by the intersection point $C$. Greater the value of b, greater the levels of $(\tilde{l}, \tilde{w})$. Here $b$ is such that the first best offer for type $H$ is given by point $A$ (at the tangency point of the iso-profit curve and the indifference curve) and the same for type $L$ is given by point $B$. That these offers are incentive compatible is evident from the fact that point $B$ lies below the lowest indifference curve of type $H$, and point $A$ lies below the lowest indifference curve of type $L$. The profit of the firm is also at the first best level. This natural separation of the types is reflected in the fact that ${ }_{L}{ }^{*}<\tilde{I}<l_{H}{ }^{*}$, which continues to hold if b lies in the critical interval specified in Proposition 1. Outside this interval, two types cannot be naturally separated.

\subsection{Second best contract}

Since $l_{L}{ }^{*}$ and $l_{H}{ }^{*}$ do not depend on b, but $\tilde{l}$ does $\left(\frac{\partial \tilde{l}(b)}{\partial b}>0\right)$, it is clear that at appropriately small values of b, we will have $\tilde{l}<l_{L}^{*}<l_{H}^{*}$, while at appropriately high values of b, we will have $l_{L}^{*}<l_{H}^{*}<\tilde{l}$. In either case, one of the two types has incentive to misrepresent when the first best offers are made. For example if we have $\tilde{l}<l_{L}^{*}<l_{H}^{*}$, points $A$ and $B$ will both lie to the right of $C$. Since $B$ will then be above the lowest 
indifference curve of type $H$, he will be better off by choosing point $B$ than point $A$.

Conversely if we had $l_{L}^{*}<l_{H}^{*}<\tilde{l}$, points $A$ and $B$ will both be to the left of point $C$, in which case type $L$ would prefer to pick point $A$ instead of point $B$. In what follows we discuss these two cases.

Case 1: $\quad b<\frac{a \sqrt{\mu_{H}}}{\mu_{L}}$

We begin by examining the individual rationality constraints (7.1) and (7.2) and noting that any $\left(l_{L}, w_{L}\right)$ that makes $I R_{L}$ bind will give type $H$ utility $u_{H}\left(l_{L}, w_{L}\right)=\frac{l_{L}^{2}}{2}$, if $H$ were to choose $\left(l_{L}, w_{L}\right)$. By doing so $H$ is better off than being self-employed, if the following holds: $u_{H}\left(l_{L}, w_{L}\right)=\frac{l_{L}^{2}}{2}>\bar{u}_{H}=\frac{b^{2}}{2 \mu_{H}}$ if $l_{L}>\frac{b}{\sqrt{\mu_{H}}}=\tilde{l}$. Therefore, the second best contract should not concede a higher utility level than $u_{H}\left(l_{L}, w_{L}\right)$. So it must make $H$ indifferent between $\left(l_{L}, w_{L}\right)$ and $\left(l_{H}, w_{H}\right)$ which is to say that $I C_{H}$ must bind. In contrast, type $L$ could not choose $\left(l_{H}, w_{H}\right)$ and ensure zero utility as long as $l_{H}>l_{L} \geq \tilde{l}$. Thus, $I R_{L}$ must bind along with $I C_{H}$.

$$
\text { Write } w_{L}=\frac{\mu_{L} l_{L}^{2}}{2} \text { from } I R_{L} \text { into } I C_{H} \text { and obtain } w_{H}=\mu_{H} \frac{l_{H}^{2}}{2}+\frac{l_{L}^{2}}{2} \text {, and then }
$$

substituting these in expected profit solve the following maximization problem (which

we call P'): $\operatorname{Max} \quad E \pi=p_{1}\left\{a l_{H}-\mu_{H} \frac{l_{H}^{2}}{2}-\frac{l_{L}^{2}}{2}\right\}+p_{2}\left\{a l_{L}-\mu_{L} \frac{l_{L}^{2}}{2}\right\} \quad$ s.t. $\quad l_{L} \geq \tilde{l}$.

Three first order conditions for maximization with respect to $l_{H}, l_{L}$ and $\lambda$ (Lagrange multiplier) respectively are 
$p_{1}\left\{a-\mu_{H} l_{H}\right\}=0$,

$-p_{1} l_{L}+p_{2}\left(a-\mu_{L} l_{L}\right)+\lambda=0$

$\lambda\left[l_{L}-\tilde{l}\right]=0$

The solutions to the above equations give rise to the optimal menu contract that we report in the following proposition.

Proposition 2: $\quad$ (a) For $b<\frac{a \sqrt{\mu_{H}}}{\mu_{L}} \gamma$ where $\gamma=\frac{p_{2} \mu_{L}}{p_{2} \mu_{L}+p_{1}}<1$, the optimal menu contract is given by $l_{L}=\frac{a}{\mu_{L}} \gamma, l_{H}=\frac{a}{\mu_{H}}$, and $w_{L}=\frac{a^{2} \gamma^{2}}{2 \mu_{L}}$, $w_{H}=\frac{a^{2}}{2 \mu_{H}}\left[1+\frac{\gamma^{2} \mu_{H}}{\mu_{L}^{2}}\right]$. These give $u_{L}=0$, and $u_{H}=\frac{a^{2} \gamma^{2}}{2 \mu_{L}^{2}}>\bar{u}_{H}$.

(b) For $b \in\left[\frac{a \sqrt{\mu_{H}}}{\mu_{L}} \gamma, \frac{a \sqrt{\mu_{H}}}{\mu_{L}}\right]$, the optimal contracts are $l_{L}=\tilde{l}, w_{L}=\tilde{w}$ and $\left(l_{H}=\frac{a}{\mu_{H}}, w_{H}=\frac{a^{2}+b^{2}}{2 \mu_{H}}\right)$. Both types just get their reservation utilities.

\section{Proof: See Appendix 2.}

Proposition 2 shows how under asymmetric information the second best contracts will involve distortions in both wage and employment. There are two ranges of $b$ to consider. If $b$ is sufficiently small (below $\frac{a \sqrt{\mu_{H}}}{\mu_{L}} \gamma$ ) we have $l_{L}>\tilde{l}$, the non-binding case.

Several points are noteworthy. First of all, the low type will be underemployed 
(by the fraction $\gamma$ ), while he receives only the reservation utility. Second, the high type's employment remains at the first best level, and his utility is strictly greater than the reservation level. This is similar to what is observed in standard screening contracts. The more efficient type gets information rent in exchange for the first best labor, and the less efficient type is given just his reservation utility; but he works less, and is also paid less, relative to the first best contract. Third, the size of the information rent conceded to the $H$ type in the form of wage premium depends on how far the $L$ type is underemployed. That is, the difference between $l_{L}$ and $\tilde{l}$ matters for the $H$ type's information rent. If $l_{L}$ could be set equal to $\tilde{l}$, type $H$ does not need to be given any information rent. So here, for type $H$, both the incentive compatibility constraint and the individual rationality constraint bind simultaneously. In part (b) of the above proposition we discuss this part. This shows that as $b$ increases, type $H$ 's outside option becomes stronger, but he begins to lose his information advantage due to the difficulty of pretending to be type $L$, because with higher $b$, the low type's offer becomes increasingly unattractive. This is essentially a reflection of the emergence of countervailing incentives that type $H$ is facing. We know from Proposition 1 that even with higher values of $b$, he will be pushed down to his reservation utility and the firm will be able to extract first best profit. Despite having private information and superior productivity, type $H$ loses all his advantage due to strengthening of his outside opportunity. His incentive to misrepresent as type $L$ is counteracted by his improved reservation utility. In fact, with further increases in $b$, the problem of countervailing incentive will get accentuated as the type $L$ will begin to have informational advantage that we address next. 
Case 2: $\quad b>\frac{a}{\sqrt{\mu_{H}}}$

We know from Proposition 1 that in this range of $b$ full information offers are not incentive compatible for type $L$, though they are so for type $H$. In this range full information employment levels are such that $l_{L}^{*}<l_{H}^{*}<\tilde{l}$. This immediately suggests that type $L$ will now have an informational advantage, similar to what type $H$ had earlier. This is clearly a case of incentive reversal. Type $L$ now may have to be given information rent for truthful revelation, and is therefore, likely to enjoy a higher utility than his reservation level. Formally, in the firm's optimization problem $I C_{L}$ and $I R_{H}$ constraints will bind.

Writing $w_{H}=\frac{\mu_{H} l_{H}^{2}}{2}+\frac{b^{2}}{2 \mu_{H}}$ from $I R_{H}$ into $I C_{L}$ and obtain $w_{L}=\mu_{L} \frac{l_{L}^{2}}{2}-\frac{l_{H}^{2}}{2}+\frac{b^{2}}{2 \mu_{H}}$, and then substituting these in expected profit we need to solve the modified maximization problem: Max $E \pi=p_{1}\left\{a l_{H}-\mu_{H} \frac{l_{H}^{2}}{2}\right\}+p_{2}\left\{a l_{L}-\mu_{L} \frac{l_{L}^{2}}{2}+\frac{l_{H}^{2}}{2}\right\}-\frac{b^{2}}{2 \mu_{H}} \quad$ s.t. $l_{H} \leq \tilde{l}$.

Following the same procedure as before we determine optimal employment, wage and information rent. The following proposition specifies the optimal contract.

Proposition 3: $\quad$ Assume $p_{1} \mu_{H}>p_{2}$

(a) If $b \in\left(\frac{a}{\sqrt{\mu_{H}}}, \frac{a}{\sqrt{\mu_{H}}} \theta\right.$ ] where $\theta=\frac{p_{1} \mu_{H}}{\left(p_{1} \mu_{H}-p_{2}\right)}>1$, the optimal menu consists of $l_{H}=\tilde{l}, w_{H}=\tilde{w}$ and $l_{L}=\frac{a}{\mu_{L}}, w_{L}=\frac{a^{2}}{2 \mu_{L}}$. The worker's utility is $u_{H}=u_{H}$ and $u_{L}=0$. 
(b) If $b \in\left(\frac{a}{\sqrt{\mu_{H}}} \theta, a\right)$, the optimal contract is $l_{H}=\frac{a}{\mu_{H}} \theta$,

$$
\begin{aligned}
& w_{H}=\frac{a^{2} \theta^{2}+b^{2}}{2 \mu_{H}} \text { and } l_{L}=\frac{a}{\mu_{L}}, w_{L}=\frac{a^{2}}{2 \mu_{L}}+\frac{1}{2 \mu_{H}}\left[b^{2}-\frac{a^{2} \theta^{2}}{\mu_{H}}\right], \\
& \text { yielding } u_{H}=u_{H} \text { and } u_{L}=\frac{1}{2 \mu_{H}}\left[b^{2}-\frac{a^{2} \theta^{2}}{\mu_{H}}\right]>0 .
\end{aligned}
$$

\section{Proof: See Appendix 3}

Proposition 3 produces a mirror image of Proposition 2. Now the incentive to misrepresent has shifted from type $H$ to type $L$. The reservation utility of $H$ has increased so much that $L$ can pretend to be $H$. Even though by pretending to be type $H$, type $L$ will have to work longer hours, but a significantly higher wage (which is necessary to employ $H$ ) more than outweighs his high disutility from work. Realizing this reversal in incentive due to very high outside opportunity of type $H$, the firm will have to distort the employment of $H$ in upward direction requiring him to work above the first best level. This will also involve increasing his wage above the first best level, but nevertheless he needs to be given just his reservation utility. This helps restricting the type $L$ 's ability to imitate $H$. Type $L$ is required to work at his first best level. But due to his informational advantage he needs to be given rent when $b$ is so great that $l_{H}$ falls strictly below $\tilde{l}$.

\subsection{Countervailing Incentives}

In many agency contexts the agent's incentive to misrepresent his 'type' (i.e. the information parameter) is not unidirectional. In some situations he may prefer to present himself as a 'high' type and in other situations as a 'low' type against the same type of offer. Generally this problem occurs when the agent's type affects not only his payoff, 
but also his reservation utility. Lewis and Sappington (1989) introduced this feature in the classic regulation model of Baron and Myerson (1982). They showed that optimal contracts would not be separating everywhere; in part it will be pooling. However, Maggi and Rodriguez-Clare (1995) re-examined this problem and showed that whether the contract will be fully separating or partly pooling depends on at what rate the agent's outside opportunity changes with respect to his type. This will also give rise to a particular pattern of inefficiency (i.e. distortion in output) and rent distribution in the second best contract. This is commonly referred to as the countervailing incentive problem in the agency literature.

Though in agency models types are generally assumed to be continuous and some of the above mentioned results of countervailing incentives are sensitive to this assumption, a similar problem occurs even with discrete types. But with discrete types the source of the change in an agent's reservation utility needs to be an exogenous parameter, which could be common knowledge. By varying this parameter one can witness countervailing incentives essentially as a comparative static outcome. Saha (2001) studied a model of this kind in the context of corruption, and Saha and Thampy (2006) followed up with a dynamic corruption problem. Both papers show that standard agency results can be linked to wider institutional variables (such as policies) and change in these institutional variables can have dramatic effects on agency relations.

In the present model, agent's types are discrete $\left(\mu_{L}\right.$ and $\left.\mu_{H}\right)$ and the high type's reservation utility does depend on his type, which is his private information. This is a necessary ingredient for countervailing incentives. But instead of changing his type continuously, we focus on a technological parameter, $b$ that exclusively affects the high 
type's reservation utility. This parameter is known to the firm, and therefore, we are essentially studying the comparative static effects of this technological parameter. In three propositions we have mapped out its various effects over the entire range of $b$. Some of the effects are, needless to say, dramatic.

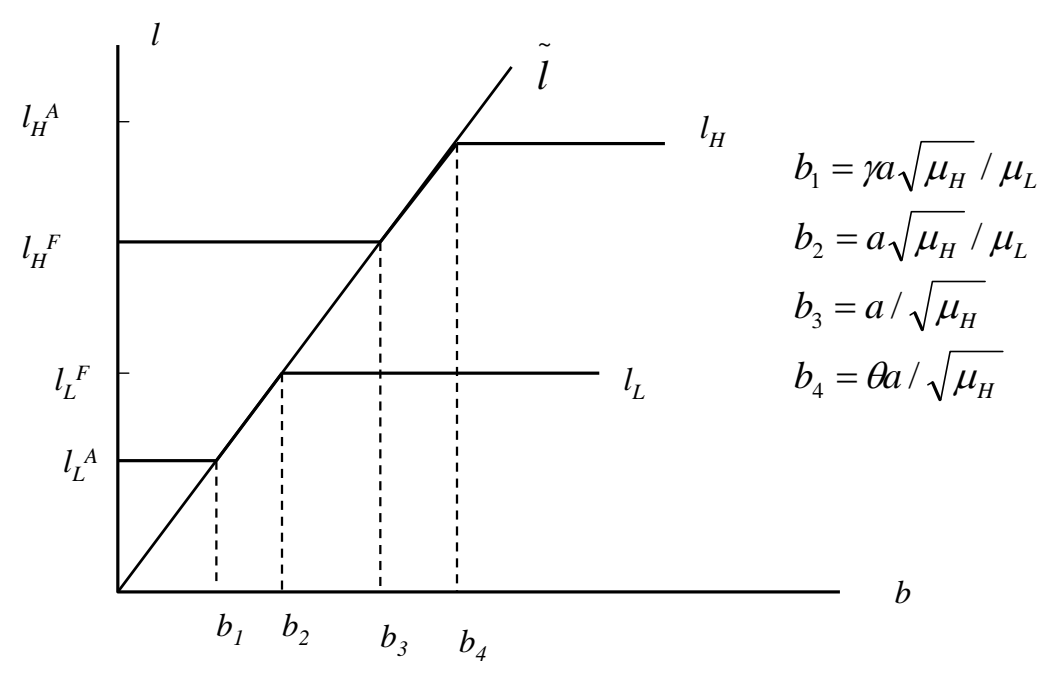

Figure 2: Optimal employment

In Figure 2 we summarize the employment effects. The two employment curves are given as $l_{L}$ and $l_{H}$. At low values of $b$ (below $b_{1}$ ), the low type is underemployed at $l_{L}^{A}$ below his full information level $l_{L}^{F}$, while the high type is employed at his full information level $l_{H}{ }^{F}$. This is shown in Proposition 2. As $b$ increases beyond $b_{1}$, the low type's employment hits the constraint $\tilde{l}$. Therefore, we have $l_{L}=\tilde{l}$ until $b$ reaches $b_{2}$. Between $b_{2}$ and $b_{3}$ employments of both types are held at their respective first best levels. This is proved in Proposition 1. Beyond $b_{3}$, employment is again distorted, but this time it is for the high type and the distortion is in the form of over-employment. Finally at $b_{4}$, 
as shown in Proposition $3, l_{H}$ stabilizes at $l_{H}{ }^{A}$. This reversal of distortion from underemployment to over-employment is necessary to separate the two types and it essentially signifies a change in the incentive regime following changes in $b$.

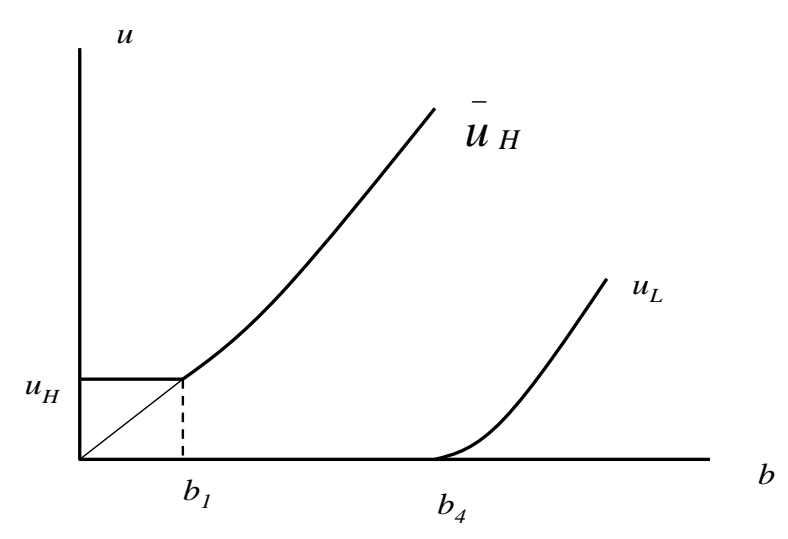

Figure 3: Worker's utility

So how does the worker's utility change in the second best contract? In the first best contract, due to the monopoly power of the firm, the worker gets only his reservation utility. In the second best contract, at least one of the two types is likely to get information rent giving him greater utility than his reservation level. If there were no countervailing incentives and if both types had the same outside opportunity, type $H$ would have had information rent over the entire range of $b$, while type $L$ would have been pinned down to his reservation utility (which is zero by assumption). But countervailing incentive causes a reversal of fortune. In the initial stage, type $H$ (up to point $b_{1}$ ) enjoys utility above his reservation level via information rent. But thereafter he is restricted to his reservation utility. When $b$ increases significantly and exceeds $b_{4}$, type L gets information rent and his utility rises above the reservation level. Thus, both types can 
earn rent, depending on the size of $b$. As is also evident, between $b_{1}$ and $b_{4}$, neither type gets rent. This is the flip side of countervailing incentives. The principal, in this case the firm, benefits from the erosion of the agent's informational advantage; it can even earn full information profit, which is indeed the case (between $b_{1}$ and $b_{4}$ ).

\section{The Optimal Strategy of the Firm}

As is suggested by Figure 3 the firm's profit tends to be greater in the presence of countervailing incentives than under standard second best contract. Nevertheless, it remains less than the first best profit overall. Moreover, in the presence of asymmetric information the firm has to commit to a menu contract which induces the workers to selfselect according to their types. So the firm has to make its decision on the basis of expected profit. In contrast, under full information it can offer a type-specific contract depending on the worker's type. As we have seen earlier, it will hire the high type up to a critical value of $b$, namely $\bar{b}$, and the low type is employable if and only if $\pi_{L}^{*} \geq \pi^{0}$. Under asymmetric information the menu contract is offered as long as $E \pi \geq \operatorname{Max}\left[p_{2} \pi_{L}^{*}, \pi^{0}\right]$. When $\pi_{L}^{*} \geq \pi^{0}$ and $p_{2}$ is such that $p_{2} \pi_{L}^{*} \geq \pi^{0}$ the least the firm can do is offer a single-point contract that only the type $L$ can accept. This will be the first best contract for type $L$, which type $H$ will not accept at all $b>\frac{a \sqrt{\mu_{H}}}{\mu_{L}}$. But such a contract will be accepted only with probability $p_{2}$. As long as $p_{2} \pi_{L}^{*} \geq \pi^{0}$ it is optimal to offer a single-point contract targeting type $L$ rather than going to the spot market, and as long as $E \pi \geq p_{2} \pi_{L}^{*}$ offering the menu contract is optimal than offering a single point contract to type $L$. 
Let the firm's expected full information profit be denoted as $E \pi^{*}$, where $E \pi^{*}=p_{1} \frac{a^{2}-b^{2}}{2 \mu_{H}}+p_{2} \frac{a^{2}}{2 \mu_{L}}$. Also write $\tilde{\pi}=a \tilde{l}-\tilde{w}$. Now utilizing the optimal wage employment as given in Propositions 1-3 we write the firm's expected profit from the menu contract as follows.

$$
\begin{aligned}
E \pi & =p_{1}\left\{\frac{a^{2}}{2 \mu_{H}}-\frac{a^{2}}{2 \mu_{L}^{2}} \gamma^{2}\right\}+p_{2}\left\{\frac{2-\gamma}{2}\right\} \frac{a^{2} \gamma}{\mu_{L}} & & \text { for } \quad b<\frac{a \sqrt{\mu_{H}}}{\mu_{L}} \gamma, \\
& =p_{1} \pi_{H}^{*}+p_{2} \tilde{\pi} & & \text { for } b \in\left[\frac{a \sqrt{\mu_{H}}}{\mu_{L}} \gamma, \frac{a \sqrt{\mu_{H}}}{\mu_{L}}\right), \\
& =E \pi^{*} & & \text { for } b \in\left[\frac{a \sqrt{\mu_{H}}}{\mu_{L}}, \frac{a}{\sqrt{\mu_{H}}}\right] \\
& =p_{1} \tilde{\pi}+p_{2} \pi_{L}^{*} & & \text { for } b \in\left(\frac{a}{\sqrt{\mu_{H}}}, \frac{a}{\sqrt{\mu_{H}}} \theta\right], \\
& =p_{1}\left\{\frac{2-\theta}{2}\right\} \frac{a^{2} \theta}{\mu_{H}}+p_{2}\left[\frac{a^{2}}{2 \mu_{L}}+\frac{a^{2} \theta^{2}}{2 \mu_{H}^{2}}\right]-\frac{b^{2}}{2 \mu_{H}} & & \text { for } b \in\left(\frac{a}{\sqrt{\mu_{H}}} \theta, a\right) .
\end{aligned}
$$

Since at most only one type can earn rent at a given value of $b$, expected profit under asymmetric information cannot exceed the same under full information. In particular, it is strictly less than the first-best expected profit everywhere except at $b \in\left[\frac{a \sqrt{\mu_{H}}}{\mu_{L}}, \frac{a}{\sqrt{\mu_{H}}}\right]$. Furthermore, $E \pi^{*}$ is strictly less than the first best profit from employing type $H, \pi_{H}{ }^{*}$. Thus we must have the following inequality: $E \pi \leq E \pi^{*}<\pi_{H}^{*}$ for $b \in(0, a)$. 
It then follows that there exists a critical value of $b$, say $\hat{b}$ which is strictly less than $\bar{b}$, such that above $\hat{b}$, the menu contract will not be offered, which implies that the high type will not be hired, if $b>\hat{b}$; only the $L$ type will be hired thereafter via a singleoffer contract. Figure 4 illustrates this point.

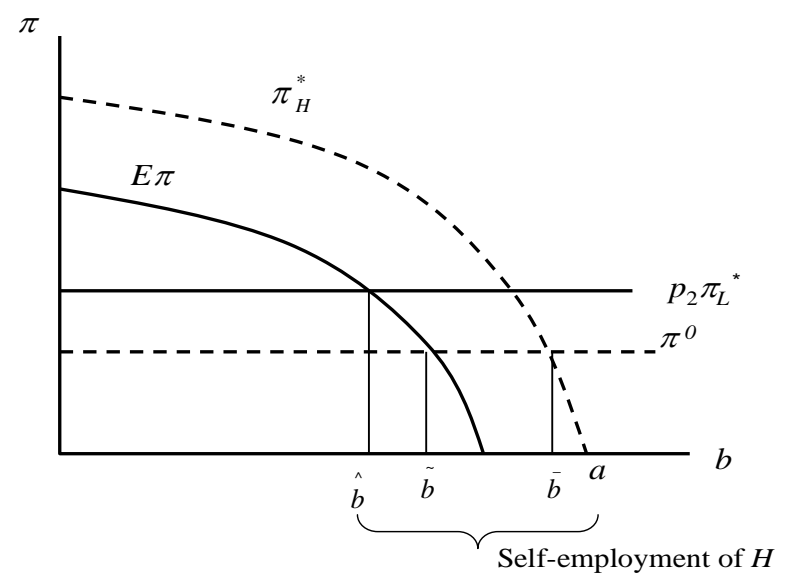

Figure 4: Firm's optimal strategy

Over the interval $(\hat{b}, a)$ type $H$ has no option but choose self-employment. Of this, however, the sub-interval $(\hat{b}, \bar{b})$ accounts for asymmetric information, and over the remaining sub-interval $(\bar{b}, a)$ self-employment occurs even under full information. If $p_{2} \pi_{L}^{*}<\pi^{0}$, the menu contract will be offered up to $\tilde{b}$. After $\tilde{b}$, the firm switches to the spot market. In this case, the firm is inclined to hire via contract a bit longer because of its relatively lower reservation profit. The high type switches to self-employment over the interval $(\tilde{b}, a)$. The range of self-employment is shorter now, but nevertheless 
asymmetric information forces the high type to switch to self-employment much earlier than he would have, if there were complete information.

Proposition 4: $\quad$ If $p_{2} \pi_{L}^{*} \geq \pi^{0}$, the firm will hire both types via contract up to a critical value of $b$, namely $\hat{b}(\hat{b}<\bar{b})$. At all $b \in(\hat{b}, a)$ it will hire only the type $L$, and type $H$ will switch to self-employment.

If $p_{2} \pi_{L}^{*}<\pi^{0}$, the critical value of $b$ will rise to, say, $\tilde{b}$ $(\hat{b}<\tilde{b}<\bar{b})$. At all $b \in(\tilde{b}, a)$ the firm switches to spot market, and both workers resort to their outside option.

\section{Concluding Remarks}

Immigrant workers and their labor force participation in the host countries have received critical attention in all concerned disciplines, principally owing to its strong implications for the well-being of the natives. Of the several studies that dealt with the patterns and consequences aspects of labor migration, only a handful raises the issue of asymmetric information across transnational labor markets to distinction. And yet, these attempts do not elucidate the explicit modalities that should define the wage-employment choices made by local employers in the wake of labor migration and in particular, when the skill levels and productivities of such migrants are private information. We impinge upon this specific gap in the subject.

The model and the results display a variety of optimal contracts offered as a menu by the local employers when asymmetric information regarding immigrants’ productivities forces them to deviate from the first best attainable under full information 
regimes. We have shown that, quite dramatically, the firm continues to offer first best contracts even under imperfect information if the production technology adopted in the alternative occupation, namely self-employment, lies within specific bounds. This not only expands the choice set facing the firms while offering profit maximizing wageemployment contracts (beyond the spot market; Oi, 1962), but also presents various implications with regard to the labor market participation of the immigrants themselves. Any value of the technology parameter outside this range does not allow efficient separation of the skill types and would drive the optimal contract to its second-best level, as regularly encountered under asymmetric information. In addition, we have shown that for such values of ' $b$ ' there are incentives on the part of both types to misrepresent their true productivities, so much so that, it gives rise to countervailing incentives for both - a situation whereby misrepresentation ceases to be unidirectional in nature. More specifically, for appropriately high values of $b$, there are incentive reversals in the sense that the skill type that then receives information rent for truthful revelation is not the one that enjoyed the same before. The menu therefore, clearly identifies specific and substantially large ranges of $b$ over which the high types choose self-employment when the contract is not offered and the high-skilled workers are not hired. Non-existence of $b$ within the specified range (the large range outside comprises of both full information and asymmetric information regimes) signifies the case whereby the better skilled would take up the outside options, which is self-employment and much in conformity with the empirical evidence.

Viewed from the immigrants’ pay-offs it is established that under first best contracts each type receives only his reservation utility, which molds into information 
rent at least for one of the types as soon as the second best contract is reached. In the absence of countervailing incentives the high type continues to receive such rent over the entire range of the technology parameter. But in the presence of it there is reversal of fortune in favor of the low type once $b$ exceeds a critical level. It is also possible that none receives any rent within a specific range of $b$. A mapping of this exhaustive set of possibilities is a considerable improvement in the understanding of how firms and immigrants interact in the labor market when information is a private good.

The pragmatic implications of this analytical exercise are quite appealing to say in the least. If the firms are able to implement a menu contract of the nature devised here, it not only helps in maximizing profits when types and productivities of non-natives are private information, but also in eroding away various inefficiencies associated with asymmetric information in the labor market. Thus, despite recognition of the fact that immigrants are a major source of skilled and non-skilled workforce in many rich countries and that the problem of asymmetric information is a natural consequence of such labor market entries, firm level policies to correct allocational and matching inefficiencies have never found prominence. The present study is undoubtedly a step in that direction too. Furthermore, ex post the optimal first and second best contracts adopted by the firms are also resonant with empirical evidence on proportional overrepresentation of immigrants in self-employment/entrepreneurship. Albeit the formal derivations of these contracts were absent, these were perhaps the best practical responses adopted by the firms (explaining the high incidence of self-employment) with the additional inferences here showing at what values/ranges of the technology parameter the corresponding wage-employment contracts offered were more appropriate than not. 
In a nutshell therefore, the study is an attempt at intellectual clarity to separate and identify explicit wage-employment contracts offered to immigrants and its consequences on the choice of occupation facing these groups. It may be extended in several other directions by including specifications of credit markets that may be necessary elements for the existence of outside options; spillover of information asymmetries onto other factor markets and so on.

\section{Appendix}

\section{Proof of Proposition 1}

(a) We need to show that when $b$ lies in the stated interval, both the $I R_{H}$ and $I R_{L}$ constraints will bind, and both the incentive constraints, $I C_{H}$ and $I C_{L}$, are satisfied. Substitute the first best solution $\left(l_{H}^{*}=\frac{a}{\mu_{H}}, l_{L}^{*}=\frac{a}{\mu_{L}}\right)$ and $w_{H}^{*}=\frac{a^{2}+b^{2}}{2 \mu_{H}}$ and $w_{L}^{*}=\frac{a^{2}}{2 \mu_{L}}$ in (5.1) and (5.2). They are satisfied with equality. Next, check the IC constraints with the first best solution. The constraints will be strictly non-binding if $b \in\left(\frac{a \sqrt{\mu_{H}}}{\mu_{L}}, \frac{a}{\sqrt{\mu_{H}}}\right)$.

When $b=\frac{a \sqrt{\mu_{H}}}{\mu_{L}}, I C_{L}$ remains strictly non-binding, but the $I C_{H}$ binds with equality. On the other hand, when $b=\frac{a}{\sqrt{\mu_{H}}}, I C_{H}$ remains strictly nonbinding, but $I C_{L}$ binds with equality. So at these two points also the first best contracts remains optimal.

(b) When $b<\frac{a \sqrt{\mu_{H}}}{\mu_{L}}$, the first best contracts fail to satisfy $I C_{H}$, which means that $H$ will strictly prefer to choose $L$ 's contract. Hence, the first best contracts are no longer 
optimal. Similarly, when $b>\frac{a}{\sqrt{\mu_{H}}}$ the first best contracts fail to satisfy $I C_{L}$, and therefore are no longer optimal. QED

\section{Proposition 2}

The following lemma may be useful in the proof.

Lemma : In an optimal menu contract the following must hold: (a) Both $I C_{H}$ and $I C_{L}$ cannot bind simultaneously. (b) At least one IR constraint must bind. (c) For any type i ( $i$ $=H, L)$ of the two constraints $I C_{i}$ and $I R_{i}$ at least one will bind.

\section{Proof of Lemma:}

(a) Suppose $I C_{H}$ and $I C_{L}$ both bind, and contracts are separating. From $I C_{H}$ we get $w_{H}=w_{L}+\mu_{H} \frac{l_{H}^{2}}{2}-\mu_{H} \frac{l_{L}^{2}}{2}$. From $I C_{L}$ we also get $w_{H}=w_{L}+\mu_{L} \frac{l_{H}^{2}}{2}-\mu_{L} \frac{l_{L}^{2}}{2}$. Setting two right hand side terms equal we derive $l_{L}=l_{H}$. That is a contradiction to our assumption that the contracts are separating.

(b) Suppose neither of $I R_{H}$ and $I R_{L}$ binds in an optimal menu contract. Then we can always find another menu contract that reduces $w_{L}$ and $w_{H}$ by an appropriately small $\varepsilon$ such that the $I C_{H}$ and $I C_{L}$ constraints remain unaffected and yet $I R_{H}$ and $I R_{L}$ still remain nonbinding. Then clearly this new contract is more profitable; hence the original set of contracts was not optimal. This is a contradiction.

(c) Without loss of generality suppose in an optimal contract, for type $L$ neither $I C_{L}$ nor $I R_{L}$ binds. That is, $w_{L}-\mu_{L} \frac{l_{L}^{2}}{2}>w_{H}-\mu_{L} \frac{l_{H}^{2}}{2}$ and $w_{L}>\mu_{L} \frac{l_{L}^{2}}{2}$, and from $I C_{H}$ we have $w_{H}-\mu_{H} \frac{l_{H}^{2}}{2} \geq w_{L}-\mu_{H} \frac{l_{L}^{2}}{2}$, while $I R_{H}$ does not depend on $w_{L}$. Then the firm can increase its profit by reducing $w_{L}$ by $\varepsilon$, such that both $I C_{L}$ and $I R_{L}$ continue to remain non-binding; such a wage reduction will clearly satisfy $I C_{H}$ and will not affect $I R_{H}$ because it does not depend on $w_{L}$. If such profit improvement is possible, then the original contract was not optimal. Hence, at least one of the two constraints (IC and IR) for any type must bind. QED. 


\section{Proof of Proposition 2:}

In the optimal (menu) contract $\left\{\left(l_{H}, w_{H}\right),\left(l_{L}, w_{L}\right)\right\}$ either $l_{L}>\tilde{l}$ or $l_{L}=\tilde{l}$. In either cases, $I R_{L}$ and $I C_{H}$ must bind, and $I R_{H}$ binds only in the second case. Our proof proceeds in several steps.

Step 1: To prove that $I R_{L}$ must bind, we assume otherwise. By part (c) of the Lemma then $I C_{L}$ must bind, and by part (b) of the Lemma, $I R_{H}$ must bind. These give $w_{H}=\mu_{H} \frac{l_{H}^{2}}{2}+\frac{b^{2}}{2 \mu_{H}}$ and $w_{L}=\frac{b^{2}}{2 \mu_{H}}-\frac{l_{H}^{2}}{2}+\mu_{L} \frac{l_{L}^{2}}{2}$. Substituting these in $u_{H}$ we get $u_{H}=\frac{b^{2}}{2 \mu_{H}}-\frac{l_{H}^{2}-l_{L}^{2}}{2}<\frac{b^{2}}{2 \mu_{H}}=\bar{u}_{H}$. But this is a contradiction. So $I R_{L}$ must bind.

Step 2: To prove that $I C_{H}$ must bind, assume otherwise. Then by part (c ) of the Lemma $I R_{H}$ must bind. From Step 1 we already know that $I R_{L}$ will bind. From these two binding constraints we get $w_{H}=\mu_{H} \frac{l_{H}^{2}}{2}+\frac{b^{2}}{2 \mu_{H}}$ and $w_{L}=\mu_{L} \frac{l_{L}^{2}}{2}$. Substitute these into the nonbinding $I C_{H}$ constraint, which then yields $l_{L}<\frac{b}{\sqrt{\mu_{H}}}=\tilde{l}$. But this violates the employment constraint specified in the problem $\mathbf{P}^{\prime}$, which is again a contradiction. So $I C_{H}$ must bind.

Step 3: From the binding constraints $I R_{L}$ and $I C_{H}$ obtain $w_{L}=\mu_{L} \frac{l_{L}^{2}}{2}$ and $w_{H}=\mu_{H} \frac{l_{H}^{2}}{2}+\frac{l_{L}^{2}}{2}$. After substituting these into the objective function we carry out the constrained maximization problem $\mathbf{P}$ ' and derive the first order conditions (7.1)-(7.3). If $l_{L}>\tilde{l}$, we have $\lambda=0$, which gives $l_{L}$ and $l_{H}$ from (7.1) and (7.2) as stated in part (a) of Proposition 1. If, however, $l_{L}=\tilde{l},(7.2)$ becomes irrelevant, though $l_{H}$ is still given by (7.1). Associated wage and utility expressions immediately follow. 
Finally, to ascertain when the employment constraint binds, check $l_{L}>\tilde{l}$ with the optimal value of $l_{L}$. This yields $b<\frac{a \sqrt{\mu_{H}}}{\mu_{L}} \gamma$ which is precisely the condition stated in part (a). For $\quad b \geq \frac{a \sqrt{\mu_{H}}}{\mu_{L}} \gamma$, we must have $l_{L}=\tilde{l}$ which is given in part (b) of the proposition. QED

\section{Proof of Proposition 3}

In the optimal contract now we have either $l_{H}<\tilde{l}$ or $l_{H}=\tilde{l}$. In either cases, $I R_{H}$ and $I C_{L}$ must bind, and $I R_{L}$ binds only in the second case. Our proof follows the analogous steps of the proof of Proposition 2.

Step 1: To prove that $I R_{H}$ must bind, we assume otherwise. By part (c) of the Lemma then $I C_{H}$ must bind, and by part (b) of the Lemma, $I R_{L}$ must bind. Obtain $w_{H}$ and $w_{L}$ from these two constraints and then substitute those into $u_{H}$ and get $u_{H}=\frac{l_{L}^{2}}{2}<\frac{b^{2}}{2 \mu_{H}}=\bar{u}_{H}$, because $l_{L}<l_{H} \leq \tilde{l}$. So this is a contradiction.

Step 2: To prove that $I C_{L}$ must bind, again we assume otherwise. From our Lemma it follows that $I R_{L}$ and $I R_{H}$ will bind. From these two binding constraints we get the expressions for $w_{H}$ and $w_{L}$ and then substitute into the non-binding $I C_{L}$ constraint, which then reduces to $l_{H}>\tilde{l}$, a contradiction to the employment constraint of problem $\mathbf{P}$ '.

Step 3: From the binding constraints $I R_{H}$ and $I C_{L}$ obtain appropriate $w_{H}$ and $w_{L}$. After substituting these into the objective function we carry out the constrained maximization problem P'. The first order condition for $l_{L}$ is $a-\mu_{L} l_{L}=0$ from which we obtain the optimal value of $l_{L}$ as given in the proposition. The first order condition with respect to $l_{H}$ is (when $l_{H}<\tilde{l}$ ) $p_{1}\left\{a-\mu_{H} l_{H}\right\}+p_{2} l_{H}=0$ from which we get $l_{H}$ as given in part (b) of the proposition. Wages and utility expressions immediately follow. 
Finally, check $l_{H}<\tilde{l}$ with the optimal value of $l_{H}$. This yields $b>\frac{a \theta}{\sqrt{\mu_{H}}}$ which is precisely the condition stated in part (b). For $b \leq \frac{a \theta}{\sqrt{\mu_{H}}}$, we must have $l_{H}=\tilde{l}$ which is given in part (a) of the proposition. QED 


\section{References}

Azariadis, Costas (1983), Employment with asymmetric information, Quarterly Journal of Economics, 98, supplement, 157-172.

Bates, Timothy (1997) Race, self-employment and upward mobility: an illusive American dream. Baltimore and London: The Woodrow Wilson Center Press, Washington. D.C., and The Johns Hopkins University Press.

Bester, Helmut (1989) Incentive-compatible long-term contracts and job rationing, Journal of Labor Economics, 7(2), 238-255.

Bonacich, Edna \& Modell, John (1981) The Economic Basis Of Ethnic Solidarity, Berkeley: University of California Press.

Borjas, George (1986) The self-employment experience of immigrants, The Journal of Human Resources 30(1), 194-204.

Borjas, George (1987) Self-selection and the earnings of immigrants, The American Economic Review 77(4), 531-53.

Borjas, George and Bronars, S. G (1989) Consumer discrimination and self-employment. Journal of Political Economy 97(4), 581-605.

Baron, D. and Myerson, R (1982) Regulating a monopolist with unknown costs, Econometrica 50, 911-930.

Chau, Nancy H. \& Stark, Oded (1999) Migration under asymmetric information and human capital formation, Review of International Economics 7(3), 455-83.

Clark, Kenneth \& Drinkwater, S (2000) Pushed out or pulled in? Self-employment among ethnic minorities in England and Wales, Labour Economics 7, 603-628.

Constant, Amelie \& Klaus Zimmermann, (2006), The Making of Entrepreneurs in Germany: Are Native Men and Immigrants Alike? Small Business Economics, 26, 3, 279300.

De Wit, Gerrit (1993) Determinants of self-employment: Studies in Contemporary Economics Series. Heidelberg: Physica-Verlag.

Duleep, H. O. \& Regets, Mark (1997) The decline in immigrant entry earnings: Less transferable skills or lower ability? Quarterly Review of Economics and Finance, 37, (Special Issue).

Dustmann, C, Fabbri, F and Preston, I (2005a) The Impact of Immigration on the British labour market, Economic Journal, 115, 507, F324-F341, 
Dustmann, C, Hatton, T and Preston, I (2005b) The Labour Market Effects of Immigration, Editorial, Economic Journal, 115, 507.

Dustmann, C and Fabbri, F (2003) Language Proficiency and Labour Market Performance of Immigrants in the UK, Economic Journal, 695-717.

Fairlie, R.W. (2005), Entrepreneurship among Disadvantaged Groups: An Analysis of the Dynamics of Self-Employment by Gender, Race, and Education, Handbook of Entrepreneurship, Volume 2, eds. Simon C. Parker, Zoltan J. Acs, and David R. Audretsch, Kluwer Academic Publishers.

Fairlie, Robert W (1996) Ethnic And Racial Entrepreneurship: A Study Of Historical And Contemporary Differences, NY and London: Garland Publishing, Inc.

Fairlie, Robert \& Meyer, Bruce (1996), The Effect of Immigration on Native SelfEmployment, Journal of Labor Economics, 21, 3, 619-650.

Fairlie, Robert \& Meyer, Bruce (1996) Ethnic and racial self-employment differences and possible explanations, The Journal of Human Resources 31(4), 757-93.

Ferguson, D and Zhang, A (1994) Strategic labour contracts, Canadian Journal of Economics, 27(3), 731-754.

Friedberg, Rachel (2000), You Can't Take It with You? Immigrant Assimilation and the Portability of Human Capital, Journal of Labor Economics, 18, 2, 221-251.

Funkhouser, E \& Trejo, Stephen (1995) The labor market skills of recent male immigrants: Evidence from the Current Population Surveys, Industrial and Labor Relations Review, 48, 792-811.

Janssen, M (2002), Catching hipos: screening, wages and competing for a job, Oxford Economic Papers, 54, 321-333.

Kar, S (2009), International Labor Migration, Asymmetric Information and Occupational Choice, Trade and Development Review, 2 (1), 34-48.

Katz, Eliakim \& Stark, Oded (1987) International migration under asymmetric information, Economic Journal 97(387), 718-726.

Kidd, M. (1993). Immigrant wage differentials and the role of self-employment in Australia, Australian Economic Papers, 32, 92-115.

LaLonde, Robert and Topel, Robert (1992) The assimilation of immigrants in the U.S. labor market. In George Borjas and Richard Freeman (eds.), Immigration and the work 
force: Economic consequences for the United States and source areas (55-89) Chicago: University of Chicago Press.

Lewis, T.R. and Sappington, D.E (1989) Countervailing incentives in agency problems. Journal of Economic Theory, 49, 294-313.

Li, Peter (1997) Self-employment among visible minority immigrants, white immigrants, and native born persons in secondary and tertiary industries of Canada. Canadian Journal of Regional Science, vol 20, issue (1-2), 103-117.

Light, Ivan (1984) Immigrant entrepreneurs in America: Koreans in Los Angeles. In Clamor At the Gates: The New American Immigration. San Francisco: ICS Press.

Maggi, G., Rodriguez-Clare, A. (1995) On countervailing incentives, Journal of Economic Theory, 66, 238-265.

Oi, Walter (1962), Labor as a quasi-fixed factor of production, Journal of Political Economy, 70, 538-55.

Razin, Eran (1992). Paths to ownership of small business among immigrants in Israeli cities and towns, The Review of Regional Studies, 22 (3), 277-96.

Saha, B (2001) Red tape, incentive bribe and the provision of subsidy, Journal of Development Economics 65, 113-133.

Saha, B and T. Thampy (2006), Extractive bribe and default in subsidized credit programs, Journal of Economic Behavior and Organization 60, 182-204.

Spence, M (1973), Job market signaling, Quarterly Journal of Economics, 87, 355-79.

(1974), Competitive and optimal responses to signals: An analysis of efficiency and distribution, Journal of Economic Theory, 7, 296-332.

Stiglitz, J (1975), The theory of screening, education and the distribution of income, American Economic Review, 65, 286-300.

Yabushita, S (1983), Theory of screening and behavior of the firm: Comment, American Economic Review, 73(1), 242-245.

Yuengert, Andrew M (1995) Testing hypotheses of immigrant self-employment, The Journal of Human Resources, 30(1), 194-204. 